\title{
Current Perspectives on the Influence of Setting and Audience on Language Choices in Multilingual Cameroon
}

\author{
Colvis Niba Ngwa \\ University of Yaounde I, Cameroon
}

\begin{abstract}
Cameroon is a dense multilingual setting in which many languages co-exist. Most of these languages are learned and are readily available for use by Cameroonians. This study probed into the complex notion of language use in a bid to ascertain in what ways context and audience influence language choice in a dense multilingual context like Cameroon. The analysis of data obtained from 100 informants in the city of Yaounde revealed that setting and audience significantly influence the language choice of a speaker and that the choice of a language reveals certain aspects of a speaker's character, attitudes and perception of the world around them.
\end{abstract}

Index Terms - language choice, multilingualism, setting, audience, current perspectives

\section{INTRODUCTION}

The multilingual nature of Cameroon has often received a lot of attention from scholars, given its rare linguistic composition. Cameroon is a Tower of Babel (Mforteh, 2007) and thus, linguistically, lives up to its name as Africa in miniature (Ngwa, 2021, p. 248). In fact, Todd (1982, p. 7) asserts that "Cameroon is among the most multilingual nations of the world", suggesting that the linguistic situation of Cameroon is immensely dense. The resultant effect of this multilingual situation of Cameroon is that many Cameroonians speak three languages, on average. In fact, sociolinguistic investigations on language choice in Cameroon (Simo Bobda, 2001; Echu, 2003; Ngefac, 2010 and Ngwa, 2021) tend to suggest that Cameroonians are at liberty to code switch from one language to another, depending on the setting and reason for speaking. Thus, linguistic borrowing, interference, code switching, loan translation, and other manifestations of language contact characterise this particularly dense multilingual context (Echu, 2003, p. 1). Literature on language use in Cameroon has noted that the language policy is notoriously poor, at the provisions laid down by the 1996 Constitution (the latest) are the stipulations that 'the Republic of Cameroon shall adopt English and French as the official languages with equal status' and that the state 'shall guarantee the promotion of bilingualism all over the territory and shall work towards the protection and promotion of national languages (Simo Bobda, 2010, p. 676).

However, as a result of the poor language policy evident in the country at the moment, most of the choices of language use are made at the individual level, depending on a number of sociolinguistic variables. This is because the complex multilingual landscape serves Cameroonians with a wide variety of languages which they use, most at times, indiscriminately. Cameroon boasts of a wealth of languages, including more than 250 indigenous languages, two official languages- English and French, Cameroon Pidgin English (also known as Kamtok in the literature) and Camfranglais. The presence of this number of languages brings out the fact that Cameroon is a multilingual context in which many languages, with different statuses and functions, co-exist. Language choice is a very important aspect of language use, especially because it not only shapes listeners' perception of the speaker, but also contributes immensely to communication and self-expression. Thus, many sociolinguistic variables, such as occupation, gender and ethnicity, may have a significant influence on the speakers' choices, but the scope of this paper is limited to setting and audience.

\section{The Linguistic Situation Of Multilingual CAMERoon}

Cameroon is a bilingual country, with English and French as its official languages. This suggests that, ideally, every Cameroonian is expected to have a thorough mastery of these two languages in order to be linguistically apt in any area in which they find themselves in the country. However, it is worth pointing out that this is not the case as French wields some considerable power over the English language and this disproportion in the use of the language has often led to some discontentment within the Anglophone community. In fact, as Simo Bobda (2001) puts it, "Anglophones have often complained about accumulated injustice perpetrated against their language, themselves and their culture". No matter the weight that is given to one language at the expense of the other, it is worth noting that both are official languages and Cameroonians are expected to learn and use them. Even though the English language seems to occupy such a marginal position in Cameroon, it is a global language (see, for instance, Graddol, 1997; Crystal, 2003 and Bolton, 2015) and recent studies (Anchimbe, 2007 and Ngefac, 2010) have underscored the fact that most Francophones 
now attend English-medium schools so as to benefit from the advantages English offers, as a global language. Added to this, it is an official language in Cameroon. English is thus a language which Cameroonians are expected to learn and use, not only because they will use it in Cameroon on a day-to-day basis, but also because it is the language of globalisation. Hence, English and French are the two languages mentioned in the country's constitution and which have made Cameroon acquire its bilingual status. Although the two languages are supposed to the equal in status, at least, as stated in the constitution, the glaring dominance of French over English today cannot be overemphasized, as French dominates in administration, in the military and in other official domains. Needless to point out that this exaggerated domination of French in a country that is supposedly bilingual has often received a lot of disgruntlement from the Anglophone community.

One major language to reckon with in multilingual Cameroon is Pidgin English, also known as Kamtok. The language has an incredible communicative potential, given that it has served communicative needs of Cameroonians for more than five hundred years (Kouega, 2003) and, today, it remains one of the most widely spoken languages in the country (Ngefac, 2010). Lexically, Cameroon Pidgin English draws its features from the colonial languages spoken in Cameroon and the indigenous languages, and many other foreign languages, given that the existence of the language dates as far back as the pre-colonial era. Thus, it has adapted itself significantly to the ecological and sociocultural and pragmatic realities of Cameroon. Functionally, it is a dominant language of wider communication in the Englishspeaking part of the country. However, it is worth pointing out that it is also used in the West and Littoral Regions, especially in Douala, Nkongsamba, Bafang, Bafoussam and Dschang (Atechi, 2006). Although the language has such a wide range of use, it is still stigmatised against in official and educational circles, as it is often seen as a deterrent to the acquisition of the English language. In fact, Alobwede (1998) insinuates that pidgin is being banned. Pidgin is thus one of the languages which are widely spoken in Cameroon.

Worthy of mention here is the fact that on the heels of CPE comes Camfranglais, a language which has been developed as a result of the contact between local languages, Pidgin English and the two official languages- English and French. According to Biloa (2004), it is a hybrid slang spoken by hawkers, blue-collar workers, unemployed Cameroonians, pupils and students. Lexically, it is constituted of words from the local Cameroonian languages, Cameroon Pidgin English, French and English. For more information on Camfranglais, see Zé Amvela (1982); Chia (1990); Echu (2001) and Kouega (2003). Although Cameroon Pidgin English is still to be generally accepted within official milieus, it has started receiving scholarly attention and it is likely to attract more scholarly attention in the near future, given its creative potential.

With regard to indigenous languages, it has been widely documented that, among the four language families in Africa, three of them are found in Cameroon. They include the Afro-Asiatic language family, the Nilo-Saharan language family and the Niger Kordofanian language family. The Niger-Kordofanian family is the most highly represented in Cameroon, while the Khoisan family is not represented at all (see Chia, 1983; Breton and Fohtung, 1991; Wolf, 2001 and Echu, 2004). They are the most used medium of oral communication. Used in homes, village meetings and traditional councils, these indigenous languages are as many and varied as the number of ethnic groups that make up Cameroon. Linguists are still to agree on the exact number of indigenous languages found in Cameroon for a number of reasons. However, in the literature the number has been placed between 250 and 300 languages (see Rosendal, 2008, p. 16). The communicative potential of these indigenous languages is pointed out in Rosendal's (2008, p. 13) assertion that "German and American missionaries preferred Cameroonian languages as Basaa, Bulu, Duala, Ewondo and Mungaka for evangelism and teaching. Bamum and Fulfulde were used for propagating Muslim faith." Following this line of thought, Mforteh (2007, p. 94), quoting SIL's (2004) report, reveals that 166 of these languages have already been standardised; 36 are being taught in some primary schools; 18 of them now have the translated version of the Holy Bible; 30 of them have the translated version of the New Testament and 30 have translated portions of the Scriptures. The knowledge of the dominant role of indigenous languages in daily communication is relevant to this study in that the indigenous language is one of the languages found in the linguistic repertoire of most, if not, all Cameroonians. In this light, they can freely combine it with other languages in the course of speaking.

\section{Language Choice in Multilingual CAMERoON}

Cameroon has often been referred to in the literature as having a complex sociolinguistic situation, where English coexists with French, Pidgin English, the indigenous languages and some emerging hybrid idioms such as Camfranglais and Mbokotok (Simo Bobda, 2001 and Ngefac, 2010). According to Simo Bobda (2001, p. 653), the country offers a particularly fertile ground for the study of patterns of language use and language choices, and the linguistic, social and educational problems that they generate. The choice of language, to begin with, can be made at the level of the state, individual, parental and other levels, and divergences and conflicts may occur between levels (Simo Bobda, 2001, p. 658). In this light, it is worth noting that, at the state level, it is known that Cameroon is a bilingual country with English as French as its official languages. In fact, in spite of the numerous languages, these are the two languages enshrined in the country's constitution. The state is thus responsible for the promotion of these languages (see Section 1(3)). Correspondingly, an individual may choose to learn or use a particular language based on the numerous advantages, mostly economic, which come with the learning of a language. In terms of language choice at the level of the individual, the motivation to learn a language is usually very high and is likely that, given that an average Cameroonian speaks at 
least three languages, the choice of a particular language would depend on the context of use and the motive for speaking. It is worth pointing out that parents equally have an invaluable role to play in the linguistic choice of their children. This mostly occurs when parents from one linguistic background send their children to study in the other subsystem of education, for instance, francophone parents sending their children to study in the Anglophone subsystem of education. Within the Cameroonian setting, such a choice made by parents for their children is usually as a result of the advantages that come with speaking English in our globalised world today (see Kouega, 1999; Anchimbe, 2007; Mforteh, 2007).

Ngefac's (2010) investigation accurately explores the linguistic choices which are made in Cameroon and explains the factors which favour or hamper the choice of use of a particular language in Cameroon, pointing out that the choice of a language has significant sociolinguistic implications (p. 160ff). With the use of Camfranglais, it was discovered that the language was mostly used among youths and the older generation had no interest in the language. This implies that the older generation may not only be conservative, as they are not open to changes or innovations, but may also consider the language childish and the language of irresponsible children. Thus, age plays a significant role in the choice of the use of Camfranglais in the Cameroon setting, as it is mostly fashionable among youths. The youths use this as an in-group language to assert their identity.

With regard to Cameroon Pidgin English, the findings reveal that, most of the informants would choose this language in order to express themselves in different areas and with close allies. As for those who were against, they noted that they do not speak Cameroon Pidgin English because it can contaminate their English. It was also revealed that Pidgin English is spoken by people across the different official language backgrounds and across other social boundaries. This implies that the language can seriously unite Cameroonians. This is because as "high as $80 \%$ of French-speaking informants and $100 \%$ of English-speaking informants above the age of 40 indicated that they use this language as a medium of communication" (Ngefac, 2010, p. 162). In this light, it can be noted that the choice of pidgin as a medium of communication among Cameroonians is widespread. As concerns the indigenous languages, Ngefac (ibid) reports that only $73 \%$ of the informants speak their indigenous language. It is worth pointing out that the choice of the indigenous languages is usually associated with ethnic groups. However, Simo Bobda (2001, p. 654) points out that a series of factors such as demographic weight, political dominance and prestige may also influence the choice of a particular mother tongue.

English and French, the two official languages, are often associated with the two and eight regions respectively where Anglophones and Francophones live. With regard to language choice, those who live in English-speaking regions would speak English, while those who live in French-speaking regions would speak French. This is because the two languages are equal in status, at least, as stated in the constitution. From the plethora of languages, language choice and use in Cameroon is often replete with phenomena such as code-switching, code mixing and interference. Language choice thus gives a researcher the opportunity to see how and in what circumstances people use a particular language. Studies such as Ngefac (2010) and Simo Bobda (2001) have greatly pointed out the circumstances which prompt languages users in Cameroon to choose or acquire a given language. These investigations into the complex phenomenon of language within the Cameroonian context have equally explained the reasons behind the choice of a particular language by users.

Sociolinguistic investigations on language choice in Cameroon (Simo Bobda, 2001; Echu, 2003 and Ngefac, 2010) tend to suggest that Cameroonians are very close to their languages and, consequently, readily use them when the need arises. These studies abound and, fortunately, are quite complementary. For instance, Ngefac (2010) focuses on two sociolinguistic variables which inform language choice- age and linguistic background- with very interesting findings, especially that most of the different, irrespective of age and linguistic background, had different motives for choosing languages. This current research endeavour builds on this to investigate the extent to which audience and setting influence the language choice of some Cameroonians. The specific focus is thus on the various choices informants make when they find themselves with specific listeners and in specific settings such as when they are at work/class with their colleagues/classmates during working hours, when they are with their colleagues/classmates out of work place or school, when they are with strangers, when they are at home and when they are at socio-cultural events.

\section{METHODOLOGY}

This study was carried out in the city of Yaounde. This area was purposively chosen given that Yaounde is a metropolitan city which, even though found in the French-speaking part of the country, attracts a lot of people who come there for business or administrative purposes. Equally, with the persistence of the crisis in the English-speaking part of the country, most Anglophones seek refuge in Yaounde. After a series of methodological considerations, a total of 100 informants from different walks of life, official language background and age groups served as informants for the study. The choice of the informants was motivated by considerations linked to profession, linguistic background, profession and age, especially because these sociolinguistic variables often have a significant influence on a speaker's linguistic output.

A questionnaire was carefully designed to find out the different languages used by the informants in the various instances listed above. The questionnaire was administered to 130 informants to enter the required information. Out of the total number of questionnaires administered, 115 of them were returned by the informants. It should be noted that 
some were not completely filled in. Thus, 100 informants were considered for the investigation because of the need to have a uniform number for easy analysis. The informants considered were thus representative of the different age groups, ranging from 15 to 45 years and above; different walks for life, drawn from both the formal and informal sectors and different levels of education. Upon return of the answered questionnaires, we quantified the informants' responses and expressed them as percentages for eventual analysis under the different subheadings. Through this method, it was possible to have ample data which enabled us ascertain the influence of setting and audience on language choice.

\section{Setting, Audience And Language Choice}

\section{A. Language Choice and Setting}

In this study, we sought to find out the informants' choice of language with regard to the different locations in which they are likely to find themselves. Some of these locations include: language choice at work or school, at home and at sociocultural events. The results got from the informants are presented subsequently.

\section{Choice of language at work/school}

We sought to find out the choice of language(s) of the informants when they are at work or school, depending on the location in which they find themselves. Work and school were selected because they are settings which are most likely to impact language choice and covered two broad domains of the informants' daily activities; this is to say that they were either students or workers. The results got are presented on the following table.

TABLE ONE

CHOICE OF LANGUAGE USED AT WORK/SCHOOL

\begin{tabular}{|l|l|l|}
\hline Response & Frequency & Percentage (\%) \\
\hline English & 35 & 35 \\
\hline English and French & 21 & 21 \\
\hline French & 15 & 15 \\
\hline English and Pidgin & 15 & 15 \\
\hline Pidgin & 07 & 07 \\
\hline French, English and Pidgin & 05 & 05 \\
\hline Null & 02 & 02 \\
\hline Total & 100 & 100 \\
\hline
\end{tabular}

From the table above, we have a clue as to the various choices of language use by the informants when they are at work or in school. In fact, as seen on the table, the most dominant language the informants choose with regard to school or work is the English language. This view is revealed in the fact that $35 \%$ of the informants attest to this. This is quite evident because English is one of the official languages and most of the informants are likely to aspire to it. Furthermore, it was noticed that $21 \%$ of the informants use both English and French. This applies to bilingual informants who use language in such settings and their choice of the language depends largely on their audience or listener(s). Equally, it was discovered that $15 \%$ of the informants speak only French, while at work or in school. $15 \%$ of the informants also pointed out that they use English and Pidgin and 7\% agreed to using only pidgin while at work or in school. Surprisingly, a percentage of the informants, that is $5 \%$, pointed out that they use three different languages, French, English and Pidgin, while at school or at work. In this light, it is worth noting that, while some professions would require workers to use even pidgin to get to a wider majority of their clients or service users, pidgin is strictly forbidden as a language to use in schools, especially in a classroom setting. On a whole, the findings in this section have revealed that the informants considered in this study often choose mostly the official languages, especially the English language, while in school or at work.

\section{Informants' language choice(s) at home}

The home is also one of the contexts in which language is used. However, it is free from some of the constraints of language choice imposed by school or work. Thus, speakers are likely to choose language more freely, compared to when they are in a formal context. It is in this light that we aimed at eliciting the language the informants use at home. Consequently, they were expected to say whether they use their indigenous language, French, English or Pidgin exclusively, or they combine it with another language or other languages. The language choice(s) of the informants is presented on the table that follows. 
TABLE TWO

CHOICE(S) OF LANGUAGE USED AT HOME By INFORMANTS

\begin{tabular}{|l|l|l|}
\hline Response & Frequency & Percentage (\%) \\
\hline Indigenous language & 25 & 25 \\
\hline Pidgin & 17 & 17 \\
\hline English and indigenous language & 12 & 12 \\
\hline English and Pidgin & 12 & 12 \\
\hline English & 10 & 10 \\
\hline French & 10 & 10 \\
\hline English and French & 07 & 07 \\
\hline French, English and indigenous language & 04 & 04 \\
\hline French and indigenous language & 03 & 03 \\
\hline Total & 100 & 100 \\
\hline
\end{tabular}

The table above reveals that the most preferred language at home is the mother tongue. This is evident in the fact that $25 \%$ of the informants acknowledged using the mother tongue at home. This is followed by Pidgin with $17 \%$. The first two languages that the informants acknowledged using at home, unfortunately, are not official languages. This suggests that speakers are more likely to choose these languages in more relaxed informal settings. That notwithstanding, we note that some of the informants in question have also use official languages at home, as revealed by $10 \%$ for English and $10 \%$ for French. Equally, we noted that some of the informants tended to combine more than one language as home. In this light we note the combination of English and indigenous language by $12 \%$ of the informants, English and pidgin by $12 \%$ of them, English and French by $7 \%$ of the informants and $3 \%$ of them accepted using both French and their mother tongue at home. Interestingly, $4 \%$ of the informants pointed out that they use English, French and the mother tongue at home. Broadly speaking, with regard to language choice at home, we note that some informants acknowledged that they may use even up to three languages at home. However, the most used language at home remains the mother tongue.

\section{Informants' language choice at socio-cultural events}

In our attempt to find out how informants use language in different settings, we also elicited the language choice(s) they are likely to make in social and cultural events. This is because, unlike school, for example, which may require strictly formal language and the home which is an informal setting in which an unofficial language may be used as seen in above, socio-cultural events, on the other hand, may require both formal and informal language. It is against this backdrop that we sought out to know the language(s) which informants use in socio-cultural events. The table below presents the results of the various language choices informants make during socio-cultural events.

TABLE THREE

LANGUAGE USED BY INFORMANTS AT SOCIO-CULTURAL EVENTS

\begin{tabular}{|l|l|l|}
\hline Response & Frequency & Percentage $(\boldsymbol{\%})$ \\
\hline English and indigenous language & 40 & 40 \\
\hline English & 17 & 17 \\
\hline Indigenous language & 13 & 13 \\
\hline Pidgin & 11 & 11 \\
\hline English and French & 10 & 10 \\
\hline French & 09 & 09 \\
\hline Total & 100 & 100 \\
\hline
\end{tabular}

True to the postulation above, most socio-cultural events as revealed in the table above are both formal and informal, we go by the view that official languages are chosen for formal settings and the indigenous language for informal settings. This is supported by the fact that $40 \%$ of the informants were of the opinion that they use both the indigenous language and the English language in socio-cultural events. This is closely followed by $17 \%$ of the informants who pointed out that they use on the English language during socio-cultural events. Correspondingly, 13\% of the informants acknowledged using their indigenous language during socio-cultural events, suggesting that this group of informants usually make such choices during village meetings or in other events involving members of the same tribe. From these statistics, it can be inferred that about $70 \%$ of language choices in socio-cultural events revolve around the English language and the indigenous language. Furthermore, pidgin was chosen by $13 \%$ of the informants, while English and French was chosen by $10 \%$ of the informants. Finally, $9 \%$ of the informants intimated that they use French in sociocultural events.

\section{B. Language Choice and Audience}

In terms of language choice and the audience, we sought to find out the various languages the informants use when they are with their colleagues out of working hours, may be relaxing somewhere, and with strangers. Each of this will be taken up in turns below, with the results presented on a table, followed by a brief analysis.

\section{Informants' choice of language with colleagues out of working hours}

In conformity with the preoccupations of the current investigation, we also sought to elicit the language choice of the informants with their colleagues or classmates out of working hours. In other words, we sought to find out informants' language choices in informal situations. They were thus expected to say whether their preferred language in such a 
situation was Pidgin, English, French or a combination of two or more languages like English and French, English and Pidgin or English, French and Pidgin. The data got for this aspect of the questionnaire are presented on the table below.

TABLE FOUR

LANGUAGE USE WiTH COLLEAGUES OUT OF WORKING HOURS

\begin{tabular}{|l|l|l|}
\hline Response & Frequency & Percentage (\%) \\
\hline Pidgin & 35 & 35 \\
\hline English and Pidgin & 30 & 30 \\
\hline English & 15 & 15 \\
\hline French & 12 & 12 \\
\hline English and French & 05 & 05 \\
\hline French, English and Pidgin & 03 & 03 \\
\hline Total & 100 & 100 \\
\hline
\end{tabular}

From the table above, we note that the informants make a series of language choices when they are out of a highly formal context such as the workplace or school. In this light, we note especially the dominance of Pidgin as $35 \%$ of the informants acknowledge using it when they are not at their jobsites or in class. This is followed by the group of informants, who, depending on the classmate or colleague they are discussing with, would choose to use either English or Pidgin, as illustrated by $30 \%$ of the informants. This points to the dominance of Pidgin in informal settings. Furthermore, while $15 \%$ of the informants acknowledge using only English, $12 \%$ of them say they use only French. To this group of informants thus, formality or informality does not really impact on their language choice, as they use the official languages with their colleagues or classmates even out of their jobsites or school. Finally, 5\% of the informants point out that they use English and French and 3\% of them note that they use English, French and pidgin with colleagues or classmates out of working hours or class respectively. Thus, language choice with colleagues or classmates out of the classroom or workplace is often characterised, perhaps depending on the interlocutor, by one, two or even three languages.

\section{Language choice of informants when they meet with strangers}

The last aspect of language choice we elicited from the informants was the language choice with strangers. In everyday language use, we do not predetermine the people we use language with. This is because we meet new people every day and when this happens, we use language to communicate with them. It is for this reason that we sought to elicit from the informants the language they use when communicating with strangers. The results got are presented on the following table.

TABLE FIVE

LANGUAGE CHOICE OF INFORMANTS WHEN THEY MEET WITH STRANGERS

\begin{tabular}{|l|l|l|}
\hline Response & Frequency & Percentage (\%) \\
\hline English & 33 & 33 \\
\hline English and French & 25 & 25 \\
\hline French & 13 & 13 \\
\hline English and Pidgin & 12 & 12 \\
\hline Pidgin & 11 & 11 \\
\hline French, English and Pidgin & 03 & 03 \\
\hline Null & 03 & 03 \\
\hline Total & 100 & 100 \\
\hline
\end{tabular}

The table above shows that the informants mostly use official languages when they meet with strangers. This is evident the fact that 33\% of them acknowledged using only English when they meet strangers, 25\% of them use English and French and $13 \%$ of the informants under study use French only. This suggests that the informants tend to meet new people in formal settings or where some degree of formality is required. Furthermore, while $12 \%$ of the informants acknowledged using both English and Pidgin when they discuss with strangers, $11 \%$ of them acknowledged using only pidgin when they discuss with strangers. Finally, 3\% of the informants use French, pidgin and English when they communicate with strangers. It is worth noting that this group of informants are multilingual and can therefore choose any language, depending on that which they interlocutor is comfortable with. It was also noted that $3 \%$ of the informants did not fill in this aspect of the questionnaire.

On a whole, with regard to language choice in a multilingual setting like Cameroon, the language the informants use depends largely on the context of language use, that is the setting and the audience. As concerns the setting, we surveyed the language choices of informants at work or school, at home and at socio-cultural events.

\section{IMPLICATIONS OF THE FINDINGS AND CONCLUSION}

The above analysis gives a clue as to the various choices of language use by the informants when they find themselves within specific locations or are in front of a particular group of interlocutors. In this light, as seen in the analysis, the most dominant language the informants choose with regard to school or work is the English language. This view is supported by $35 \%$ of the informants who attest to this. Broadly speaking, with regard to language choice at home, we note that some informants acknowledged that they may use even up to three languages at home. However, the 
most used language at home remains the mother tongue. Most socio-cultural events, as revealed in the analysis, are both formal and informal. Consequently, official languages are chosen for formal settings and the indigenous language for informal ones. This is supported by the fact that $40 \%$ of the informants were of the opinion that they use both the indigenous language and the English language in socio-cultural events. From these statistics, it can be inferred that about $70 \%$ of language choices in socio-cultural events revolve around the English language and the indigenous languages. The informants make a series of language choices when they are out of a highly formal context such as the workplace or school. In this light, we note, especially, the dominance of Pidgin as $35 \%$ of the informants acknowledge using it when they are not at their jobsites or in class. Thus, language choices of the informants with their colleagues or classmates out of the classroom or workplace are often characterised, perhaps depending on the interlocutor, by one, two or even three languages. The informants mostly use official languages when they meet with strangers. This is evident the fact that $33 \%$ of them acknowledged using only English when they meet strangers, 25\% of them use English and French and $13 \%$ of the informants under study use French only.

In the light of the above, speaker's location plays a major role in determining their language choices. This is especially because the setting can either be formal or informal. It is commonplace knowledge that formal settings would require a speaker to adopt not only the official language, but also the formal forms of that language, given that language choice is often governed by rules related to appropriateness in speech and style. The use of formal language in formal settings also has some metalinguistic implications, especially the fact that it commands respect from the listener(s). On the other hand, informal settings would also entail that a speaker use a language of phatic communion or more casual forms of a language in order to appeal to the listeners' sense of togetherness or hospitality. Whatever the case may be, every setting demands the choice of a particular language in order for the speaker to be 'linguistically appropriate' in that setting.

Equally, another factor which is most likely to determine language choice in multilingual Cameroon is the audience or interlocutor(s). This is more so because, as revealed by the analysis, people would use familiar or an unofficial language more with friends than with strangers. In this light, it is thus worth pointing out that a particular speaker may tend to choose different languages or groups of languages, depending on the person to whom the message is destined. Such alternation in language choice is mostly because, first, the goal of every speaker is to be understood; thus, they use any code through which the communicative function of language can be fulfilled. Second, speakers also need to appeal to the listener(s) sense of togetherness. That is, they need to show that they are one with their listeners. In this light, language choice becomes very important.

From the findings of the study, one can observe that, in a multilingual setting like Cameroon, language choices transcend linguistic considerations such as speaking and listening or mere communication. They reveal aspects of a speaker's character, their perception of the interlocutor and the attitude they want their interlocutors to develop towards them. Given such importance accorded to language choice by language users, the choice a language by a user within a given setting or with a particular interlocutor is often guided by a series of considerations. This explains why, within a given setting, most language users tend to make different choices.

\section{REFERENCES}

[1] Alobwede d'Epie, C. (1998). "Banning Pidgin English in Cameroon?” English Today 14(1): 54-60.

[2] Anchimbe, E. (2007). "Linguabridity: Redefining linguistic identities among children in urban areas." In: Anchimbe, A.E. (ed.), Linguistic Identity in Postcolonial Multilingual Spaces, pp. 66-86.

[3] Atechi, S. N. (2006). The Intelligibility of Native and Non-Native English Speech. Gottingen:Cuvillier Verlag.

[4] Biloa, E. (2004). "Loans from European Languages in African Languages: Intercultural Relationship and Necessity". http://www.inst.at/trans/15Nr/07-2/echu 15.htm. retrieved on August 15, 2015.

[5] Bolton, K. (2006). "World Englishes Today.” In Kachru, B. et al. (eds.) The Handbook of World Englishes. Oxford: Blackwell, 240-270.

[6] Breton, R. and B. Fohtung. (1991). Atlas Administratif des Langues Nationales du Cameroun. Yaoundé, Paris: CERDOTOLA, CREA - ACCT..

[7] Chia, E. (1990). "The New Speech Forms of a Rapidly Growing City: Pidgin French and Camfranglais in Yaounde" in Annales de la Faculté des Lettres et Sciences Humaines, Université de Yaoundé, vol. VI, nos. 1 et 2, pp. 102-127.

[8] Chia, E. (1983). "Cameroon Home Languages," In Kofele-Kale, Ndiva (ed.). An African Experience in Nation building: The Bilingual Cameroon Republic Since Reunification, 281-311.Boulder, Co: Westview.

[9] Crystal, D. (2003). English as a Global Language. 2nd ed. Cambridge: Cambridge University Press.

[10] Echu, G. (2003). "Multilingualism as a resource: The lexical Appropriation of Cameroon Indigenous Languages by English and French." TRA0S. Internet-Zeitschrift für Kulturwissenschaften. No. 13/2003. www.inst.at/trans/13Nr/echu13.htm. Consulted on November 2, 2019.

[11] Echu, G. (2004). The language question in Cameroon. Linguistik Online, 18 (1).http://www.linguistikonline.de/18_04/echu.html. Consulted on November 2, 2019.

[12] Graddol, D. (1997). The Future of English. London: British Council.

[13] Kouega, J. P. (1999) Forty years of official bilingualism in Cameroon: An appraisal. English Today 15(4): 38-43.

[14] Kouega, J. P. (2003). "Word Formative Processes in Camfranglais.” World Englishes, 22(4): 511-538.

[15] Mforteh, S. (2007). "In search of new identities in multilingual Cameroon." In: Anchimbe, A.E. (ed.), Linguistic Identity in Postcolonial Multilingual Spaces, pp. 87-101. 
[16] Ngefac, A. (2010). “Linguistic Choices in Postcolonial Multilingual Cameroon.” Nordic Journal of African Studies, 19(3): 149-164.

[17] Ngwa, C. N. (2021). "An Investigation into Patterns of Linguistic Combinations in Multilingual Cameroon." Revue Della/Afrique, 3(7): 248-265.

[18] Rosendal, T. (2008). Multilingual Cameroon: Policy, Practice, Problems and Solutions. Gothenburg: Africana Informal Series.

[19] SIL (2004). http://www.silcam.org/folder030401/page.php. Consulted on September 2, 2015.

[20] Simo Bobda, A. (2001). Varying Statuses and Perceptions of English in Cameroon: A diachronic and synchronic analysis. TRANS11. (http://www.inst.at/trans/11Nr/bobda11.htm). Retrieved on February 15, 2014.

[21] Simo Bobda, A. (2010). "Cameroon: Which Language, when and why?" In Kirkpatrick, A. (ed). The Routledge Handbook of World Englishes. London: Routledge.

[22] Todd, L. (1982). "Language Options for Education in a Multilingual Society: Cameroon". In: Kennedy, Chris (ed): Language Planning and Language Education. London: 160-171.

[23] Wolf, H.-G. (2001). "English in Cameroon". Contributions to the Sociology of Language 85. Berlin: Mouton de Gruyter.

[24] Ze Amvela, E. (1983). "The Franglais Phenomenon: Lexical Interference and Language Mixing in the United Cameroon" in Bulletin de l'A.E.L.I.A, No 6, pp. 419-429.

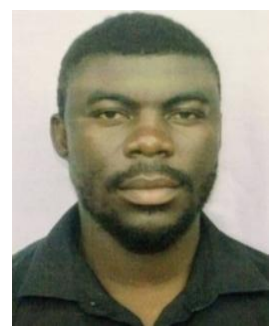

Ngwa Colvis Niba holds a Master's Degree in English Language and a professional certificate in ELT from the University of Yaounde 1, Cameroon, where he is currently completing a thesis on the mutual intelligibility of non-native Englishes, with focus on Cameroon English and Tanzanian English. He is a graduate assistant in English at the Higher Teacher Training College, Bertoua under the University of Ngaoundere where he has been teaching many language and research-related courses for the past four years. He has presented papers at different conferences organised by the Universities of Yaounde and Bamenda. He is author of many scholarly articles, some of which have appeared in the Journal of Language Teaching and Research and Revue Della/Afrique. 